\title{
Validation Strategy for User-specific Map Products for the European Copernicus Security Service
}

\author{
Sebastian d'Oleire-Oltmanns, Barbara Riedler, Lena Pernkopf, Elisabeth Weinke \\ and Stefan Lang \\ Department of Geoinformatics - Z_GIS, University of Salzburg, Austria · \\ sebastian.doleire-oltmanns@sbg.ac.at
}

Full paper double blind review

\begin{abstract}
The increasing demand for and availability of (geo-)data products in the EC-ESA conjoint Copernicus initiative has boosted geospatial information services in a range of societal domains. Addressing the domain of human security we developed a validation strategy for user-specific map products. This validation strategy is based on four categories (relevance, impact, readability, transferability) that each consists of selected validation attributes. The developed expert-based scaling approach follows the Likert scale, which results in an individual grading per product. In addition to the quantitative assessment, also verbal descriptions of positive and negative aspects, as well as recommendations are provided. All validation outcomes are communicated via a web-based platform, which was developed using open-source software environments. The presentation of the validation outcomes in this intuitive manner supports the continuous improvement of the production within the service. In addition, the validation strategy is intended to be adaptive to different contexts. This assures the implementation in operational services and further application fields, where it is necessary to assure, maintain, and improve the quality of the products in the long run.
\end{abstract}

\section{Introduction}

Creating geospatial information products such as printed paper maps or any digital (geo-) data has become a standard exercise for service providers from both, academic and commercial sectors. The EC-ESA conjoint Copernicus initiative has boosted the production and delivery of geospatial information services in a range of societal domains. Here we address the domain of human security. A variety of different thematic contents may be integrated in such information products: reference maps that document the current situation for a specific moment in time, change detection analysis to monitor a certain development, population distribution/density maps, and many more. These products support the work of different institutions such as aid organizations, political decision makers, companies from different sectors, as well as scientific institutions. Hence, data providers supply a dynamic and still growing market.

Next to the technical design of geospatial information products, the assessment of their quality, as well as the match with the specific user needs, is an essential step in the production workflow, before and after the final delivery. This shall ensure the quality of delivered

GI_Forum - Journal for Geographic Information Science, 1-2015.

(c) Herbert Wichmann Verlag, VDE VERLAG GMBH, Berlin/Offenbach. ISBN 978-3-87907-558-4.

(C) ÖAW Verlag, Wien. ISSN 2308-1708, doi:10.1553/giscience2015s438. 
and future products, as well as the match of the contained information with user requirements expressed in advance. This procedure can be considered the (user) validation of the product. According to O'Keefe, validation means "to build the right system", whereas verification means "to build a system right" (O'KEEFE 1982, 162). At a first glance, the difference seems to be little, but in fact it is crucial as it defines validation as a mandatory step within a production workflow that builds on user requirements. In other words, beyond answering the question "Are we doing the right thing right?" validation is required to answer the question "Are we doing the right thing?" (ZEIL \& LANG 2009).

\section{Project Context}

The presented validation protocol for geospatial information products was developed in the context of the FP7-funded project G-NEXT-Pre-operational Copernicus services in support of EU external action. In total, 15 partners collaborate in this project for more than two years $(01 / 2013-06 / 2015)$.

The aim of the G-NEXT project is to create a pre-operational service in support of EU external action that may be continuously offered by the European Union (EU) to all member states and authorized users. The general service workflow starts with user requests that define user needs, which should be covered by one or more products within the G-NEXT Product Portfolio. If the user request fulfils the scope of the G-NEXT service, the service is activated. The next step is the production phase, which includes a check of the products' technical coherence, as well as the degree of match with the user needs. The final products of selected activations undergo a detailed validation.

During the runtime of the project, a number of obstacles and challenges were identified, as the work carried out was under 'real conditions'. The need for a constant improvement of the workflow stimulated the development of a universally adaptable validation strategy, as presented in the following sections. Validation protocols that were created in related projects, such as SAFER (BROGLIA et al. 2010), were used as a starting point for the presented approach.

\section{Methodology for the Validation}

To validate often very heterogeneous products, an expert-based scaling approach following the Likert scale (LIKERT 1932) was chosen. For the presented validation strategy, different validation attributes are individually graded on a twelve-point scale. These grading values are then aggregated per validation category, and subsequently aggregated to a product score. Usually, an activation in the abovementioned sense is composed of several products. Thus, the respective product scores together with the user feedback are aggregated to an activation score. This provides an overall estimation of the quality of the whole activation, and allows for a comparison of different activations (also over time). In addition to this quantitative assessment, detailed verbal descriptions are available to the service providers. Finally, the results are provided on the web-based G-NEXT Validation platform. 


\subsection{Validation Concept and Integration into the Production Workflow}

The validation of the G-NEXT service is carried out for selected activations and the respective products after the delivery of the products to the user. Its results are integrated in the GNEXT workflow as a key aspect for the improvement of products and evolution of the service.

Products are validated applying the validation attributes that can be assigned to the four categories, i.e. 1) relevance, 2) impact, 3) readability, and 4) transferability (Table 1). These four categories are based on the outcomes of previous project work in the context of Copernicus that has been taking place for several years now. The intention has been and still is to come up with a generally applicable validation method. Further details may be found in BROGLIA et al. (2010).

Table 1: Validation attributes

\begin{tabular}{|c|c|c|}
\hline Category & Attribute & Additional information \\
\hline \multirow[t]{7}{*}{ Relevance } & Spatial coverage & $\begin{array}{l}\text { Spatial coverage refers to the map extent, which should cover the user- } \\
\text { defined AOI. A full coverage of both data and analysis results is important } \\
\text { for the relevance of the product. }\end{array}$ \\
\hline & Close-up maps & $\begin{array}{l}\text { Close-up maps provide detailed information about relevant results at a fine } \\
\text { scale and increase the information content of the whole product (if appli- } \\
\text { cable for the specific product). A proper design of close-up maps is im- } \\
\text { portant to provide an added value. }\end{array}$ \\
\hline & Overview map & $\begin{array}{l}\text { Overview maps are generalized, smaller-scale maps that show the limits of } \\
\text { the AOI(s) and facilitate orientation. }\end{array}$ \\
\hline & $\begin{array}{l}\text { Cartographic } \\
\text { information }\end{array}$ & $\begin{array}{l}\text { Basic cartographic elements such as scale bar, north arrow, and projection } \\
\text { information are standard elements of a map that allow a better orientation. }\end{array}$ \\
\hline & $\begin{array}{l}\text { Legend } \\
\text { consistency }\end{array}$ & $\begin{array}{l}\text { The legend provides detailed information about the symbology of features } \\
\text { in the map. A consistency between symbols in the legend and the map is } \\
\text { essential for an easy identification of features. }\end{array}$ \\
\hline & $\begin{array}{l}\text { Content of text } \\
\text { elements }\end{array}$ & $\begin{array}{l}\text { A comprehensible content of text elements facilitates the understanding of } \\
\text { information provided by the map. Map titles should provide a self-explana- } \\
\text { tory description of the product. The interpretation text should include } \\
\text { information about the purpose of the product in relation to the user needs, } \\
\text { the production methodology, as well as a short interpretation of results. }\end{array}$ \\
\hline & $\begin{array}{l}\text { Match with infor- } \\
\text { mation needs }\end{array}$ & $\begin{array}{l}\text { The match between the provided product and the information needs de- } \\
\text { fined by the user is essential for the relevance of the product and depends } \\
\text { on the quality of translation of user needs into a set of layers. This refers to } \\
\text { existing and consistent semantics of required layers. }\end{array}$ \\
\hline \multirow[t]{3}{*}{ Impact } & $\begin{array}{l}\text { Temporal ade- } \\
\text { quacy }\end{array}$ & $\begin{array}{l}\text { Temporal adequacy refers to the acquisition date of input data. An ade- } \\
\text { quate choice is essential to address user needs and products with a high } \\
\text { impact. }\end{array}$ \\
\hline & $\begin{array}{l}\text { Cartographic } \\
\text { design }\end{array}$ & $\begin{array}{l}\text { Cartographic design refers to the main map. An appealing design in com- } \\
\text { bination with relevant information that is easy to extract has a great influ- } \\
\text { ence on the use and impact of the product. }\end{array}$ \\
\hline & $\begin{array}{l}\text { Effectiveness of } \\
\text { visual information } \\
\text { delivery }\end{array}$ & $\begin{array}{l}\text { Relevant information should be evident to facilitate a fast communication } \\
\text { of the main results, and to increase the impact of the product. }\end{array}$ \\
\hline
\end{tabular}




\begin{tabular}{lll}
\hline Readability & Symbology & $\begin{array}{l}\text { The symbology of features is one of the key elements for the readability of } \\
\text { a product, facilitates information extraction, and has a major influence on } \\
\text { the understandability of the product. }\end{array}$ \\
\hline $\begin{array}{l}\text { Overlap between } \\
\text { layers }\end{array}$ & $\begin{array}{l}\text { Overlaps between layers can be problematic if relevant features are cov- } \\
\text { ered by others and thus not visible. }\end{array}$ \\
\hline $\begin{array}{l}\text { Adequacy of } \\
\text { geometry type }\end{array}$ & $\begin{array}{l}\text { An adequate spatial representation of features (point, line, or polygon } \\
\text { symbols) is important for the composition and readability of the map } \\
\text { product. }\end{array}$ \\
\hline $\begin{array}{l}\text { Legend } \\
\text { appearance }\end{array}$ & $\begin{array}{l}\text { The legend appearance is not only relevant for its readability, but its ar- } \\
\text { rangement also affects the availability of space for other elements. }\end{array}$ \\
\hline $\begin{array}{l}\text { Labels } \\
\text { Text elements }\end{array}$ & $\begin{array}{l}\text { Labels may be considered as part of the symbology but due to their im- } \\
\text { portance for the readability and understandability of the product they are } \\
\text { separately evaluated. }\end{array}$ \\
$\begin{array}{ll}\text { The readability of text elements in terms of spelling, linguistic quality and } \\
\text { font size is important for the overall readability of the text. }\end{array}$ \\
\hline $\begin{array}{l}\text { Graticule/grid } \\
\text { ability }\end{array}$ & $\begin{array}{l}\text { Graticules and grids are mandatory elements that facilitate the orientation } \\
\text { on the map and the extraction of information about the location of features. }\end{array}$ \\
$\begin{array}{l}\text { Repeatability of } \\
\text { processing steps }\end{array}$ & $\begin{array}{l}\text { The transferability strongly depends on how site-specific the methodology } \\
\text { and the single processing steps are, which may reduce the potential for } \\
\text { (semi-) automated processes. }\end{array}$ \\
\hline $\begin{array}{l}\text { Objectivity of } \\
\text { results }\end{array}$ & $\begin{array}{l}\text { The objectivity of results is important for the quality and repeatability of } \\
\text { results, as well as for a potential transfer of methods to other sites. }\end{array}$ \\
\hline sources & $\begin{array}{l}\text { The availability of input data is a key aspect for the transferability of } \\
\text { methods, which involves cost, time and/or scale aspects. }\end{array}$ \\
\hline
\end{tabular}

A twelve-point scale from 0 to 5 with a 0.5 interval is applied. The value 0 is the lowest possible value, representing missing or very poor attributes, and 5 is the highest possible value, representing excellent attributes. Each attribute is evaluated based on guiding questions, which cover the heterogeneous range of products to be validated in a best possible manner. The resulting grading system is independent from the number of underlying questions: per attribute, all answers to the respective questions are aggregated in one final value, which enables the comparison of all attributes. In addition to this quantitative approach detailed feedback as verbal descriptions on attribute level are provided.

The validation is carried out on two different levels: the product level, and the activation level. On product level, each product is assessed by applying the validation attributes. The result is a grading score per product and per attribute, which enables an identification of product specific aspects in terms of positive and/or negative points that require improvement. The grading values of all individual attributes are then cumulated as mean value per category (relevance, impact, readability, transferability). This in turn allows the comparison of specific aspects between different products. Finally, the product score represents the mean value of all validation attributes per product. It provides an overall estimation of the quality of each product and furthermore allows the comparison of products.

On activation level, the results on product level are again aggregated per attribute, category, and finally subsumed in an overall assessment, the activation score. This provides an overall estimation of the quality of the whole activation and allows for a comparison of different activations, which is of high importance in order to monitor the overall development and progress of the service over time. The activation score includes the mean value of the product scores, selected aspects of the user feedback. The user feedback is provided on the level 
of the whole activation and does not address individual products. Therefore, it is only included on activation level, and not on product level. The grading system of the user feedback (scores between 1 as the lowest and 9 as the highest value) is translated into the grading system of the validation (0-5) to make them comparable. The additional attribute "Corporate identity" was included in the category "Readability" on activation level. All aggregations of the validation are carried out using equal weights (applies for mean value of categories, mean product score, and mean activation score).

\subsection{Technical Implementation on a Web-based Platform}

The use of existing content management systems is well suited for the implementation of web-based validation platforms. The project team developed and implemented an own solution to be as flexible as possible during the project lifetime and beyond. In addition, the specific requirements to the user interface and functionalities of the platform differed from the usual implementations of web platforms.

The web-based platform was developed based on open-source technologies. We used open source technologies with Java Script HTML5, CCS, and JQuery on the client side. On the server side Java Server Pages and Java Servlets were used to develop the database connection and middleware components. The data of the web-based platform were managed using a Postgres data management system.

Authorization routines were implemented to allow only restricted users access to the main pages of the platform. Only authorized users are able to edit all parameters of the platform, e.g. to add, modify and delete activations and products.

\section{$4 \quad$ Validation Outcome}

Validation results are provided to all project partners via the web-based platform, on which the results are illustrated in a comprehensive manner on two different levels: (1) activation level with aggregated values of single products for each attribute, a mean grading for each category and an overall score for the activation (Fig. 1), and (2) product level with a detailed evaluation of each attribute (Fig. 2), a mean grading for each category, and an overall score for the product. 


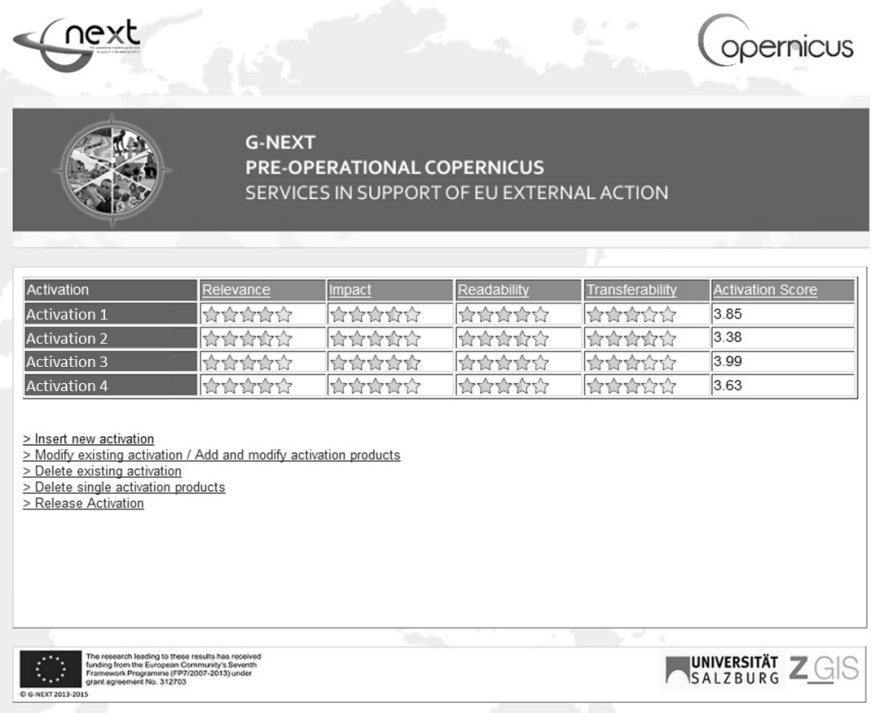

Fig. 1:

Validation results on activation level showing the relevance, impact, readability, and transferability of products

For easy interpretation the rating of attributes and categories are provided as a five-point star rating, with the actual activation score provided in numerical from (Fig. 1).

\begin{tabular}{|c|c|c|c|c|}
\hline Attribute & & $+1-$ & & Rating \\
\hline Spatial coverage $\mathbf{\theta}$ & VHR data fully cover the LOI & & & \\
\hline Close-up maps $\mathbf{\theta}$ & $\begin{array}{l}\text { if available, close-up maps allow } \\
\text { for an identification of critical } \\
\text { infrastructure }\end{array}$ & $\begin{array}{l}\text { loom factor could be increased } \\
\text { colour of title and scale bar } \\
\text { could be improved }\end{array}$ & & \\
\hline Overview map $\mathbf{\theta}$ & $\begin{array}{l}\text { overview maps allow for an easy } \\
\text { identification of the location of } \\
\text { the AOI }\end{array}$ & & $\begin{array}{l}\text { country names are not well } \\
\text { readable }\end{array}$ & \\
\hline Cartographic information $\mathbf{O}$ & $\begin{array}{l}\text { lll necessary elements are } \\
\text { present }\end{array}$ & & & \\
\hline Legend consistency $\theta$ & $\begin{array}{l}\text { most map features can be } \\
\text { assigned to the legend }\end{array}$ & & & \\
\hline $\begin{array}{l}\text { Content of text elements (title, } \\
\text { interpretation text, disclaimer) }\end{array}$ & \begin{tabular}{|l|} 
all compulsory text elements are \\
present \\
link to user needs is present
\end{tabular} & $\begin{array}{l}\text { order of main title and subtitle } \\
\text { could be changed }\end{array}$ & \begin{tabular}{|l|} 
description of methodology is \\
missing \\
interpretation of results is missing
\end{tabular} & $\hat{\imath} \hat{n}$ \\
\hline $\begin{array}{l}\text { Match with information needs } \\
\text { (Product Design) }\end{array}$ & $\begin{array}{l}\text { the wording mostly matches the } \\
\text { PD }\end{array}$ & & $\begin{array}{l}\text { information about the runway } \\
\text { condition is missing }\end{array}$ & \\
\hline
\end{tabular}

Fig. 2: Validation results on product level showing the attributes of the validation category 'relevance'

In addition to the grading, comprehensive statements are provided on each individual attribute, describing well implemented tasks, as well as missing features and recommendations for future products (Fig. 2). 


\section{Conclusion and Outlook}

The developed validation strategy provides important feedback to all parties involved in the workflow. The users receive statements on the overall quality of the delivered product(s), including an assessment on relevance and impact.

Together with the delivered validation report and the outcomes presented on the web-based platform, the service providers receive valuable information for continuous improvement of the production workflow. This improvement shall lead to more user-oriented products in accordance with a defined product portfolio.

A certain degree of subjectivity remains with the expert-based grading of individual attributes. Still, this may be overcome with an increased number of validations. After the validation of a greater number of activations, only product specific aspects will remain subjective, whereas the overall assessment poses a neutral and more objective statement on the overall quality of the products and finally of the service. In order to arrive at that point, also the validation approach as such requires continuous improvement to fit the respective validation context as best as possible (in terms of products or activations).

It is also important to include more detailed user feedback, which allows for a better synchronization of user needs and production workflow.

The validation strategy is intended to be adaptive to different contexts. This assures the implementation in operational services and further application fields where it is necessary to assure, maintain, and improve the quality of the products in the long run.

\section{Acknowledgements}

Funding for this work has been received from the from the European Union's Seventh Framework Programme (FP7/2007-2013) under grant agreement $n^{\circ} 312703$, G-NEXT (Geospatial services in support of EU external action).

\section{References}

Broglia, M., Corbane, C., Carrion, D., Lemoine, G. \& Pesaresi, M. (2010), Validation Protocol for Emergency Response Geo-information Products. EUR 24496 EN - Joint Research Centre - Institute for the Protection and Security of the Citizen. Luxembourg: Publications Office of the European Union. 52 p.

LiKeRT, R. (1932), A Technique for the Measurement of Attitudes. Archives of Psychology, 140, 1-55.

O’Keefe, R. M., BALCI, O. \& Smith, E. P. (1982), Validating Expert System Performance. IEEE Expert Winter. In: HoPPE, T., Validation of User Intention. In: Current Trends in Knowledge Acquisition; WielingA, B.; Gaines, B.; VAn Someren, M., Eds. IOS, Amsterdam, 1990, $388 \mathrm{p}$.

ZeIL, P. \& LANG, S. (2009), Do have clients a role in validation? In: Corbane, C. et al. (Eds.), VALgEO 2009, JRC, EUR 24082 EN-2009, 143-147. 